\title{
KECERDASAN INTELEKTUAL (IQ), KECERDASAN EMOSIONAL (EQ) DAN KECERDASAN SPIRITUAL MEMPENGARUHI KINERJA KARYAWAN PT Perusahaan Gas Negara (Persero) Tbk AREA BEKASI
}

\author{
R. Endah Adinda Bestari
}

Marhalinda

2017

\begin{abstract}
This research was conducted to determine the effect of Intelligence Quotient, Emotional Quotient and Spiritual Quotient on Employee Performance at PT Perusahaan Gas Negara (Persero) Tbk Sales Area Bekasi.

The method was used is descriptive quantitative method. Samples were taken by the literati amounted to 59 respondents. Observation, interviews and questionnaires were used for the method of data collection. In the statistical analysis, the literati is using Statistical Package For Social Sciences SPSS Program 22.0 version to searched of validity, reliability, single and multiple regression, $t$ test and $f$ test. From the data processing obtained $r=0,942$ with the multiple determination value amounted to $87,9 \%$ and the $12,1 \%$ was determined by the other factors. The multiple regression value was shown by the $F$ test $(\alpha=0,05)$ that obtained $f_{\text {hitung }}$ value 105,105 and $f_{\text {tabel }}$ value 3,23. Which is means $f_{\text {hitung }}>f_{\text {tabel, }}$, therefor $H_{0}$ was rejected and $H_{a}$ accepted. This shows that there is very sicnicant influence between Intelligence Quotient $\left(X_{1}\right)$, Emotional Quotient $\left(X_{2}\right)$ and Spiritual Quotient $\left(X_{3}\right)$ on Employee Performance (Y) at PT Perusahaan Gas Negara (Persero) Tbk Sales Area Bekasi.
\end{abstract}

Keywords: Intelligence Quotient, Emotional Quotient, Spiritual Quotient and Employee Performance

\begin{abstract}
Abstraksi
Penelitian ini dilakukan untuk mengetahui tentang kecerdasan intelektual, kecerdasan emosional dan kecerdasan spiritual mempengaruhi kinerja karyawan di PT Perusahaan Gas Negara (Persero) Tbk untuk Sales Area Bekasi.

Metode yang digunakan adalah metode deskrptif yang bersifat kuantitaf. Sampel yang diambil oleh peneliti berjumlah 44 reponden. Dalam metode pengumpulan data menggunakan teknik observasi, wawancara dan kuesioner. Dalam analisis statistik, penulis menggunakan Program Stratistical Package for Social Scienses (SPSS) versi 22.0 untuk mencari validitas, reliabilitas, regresi berganda, uji t dan uji f. dari pengolahan data yang dilakukan dengan program SPSS tersebut, didapat $r=0,942$ dengan nilai determinasi berganda sebesar $87,9 \%$ dan sisanya $12,1 \%$ menunjukkan kontribusi dari faktor lainnya. Untuk nilai regresi berganda didapatkan dan untuk uji $F$ dengan $\alpha=0,05$ didapat nilai $f_{\text {hitung }}$ sebesar 105,105 dan nilai $\mathrm{f}_{\text {tabel }}$ sebesar 3,23. Maka dapat diartikan bahwa $\mathrm{H}_{0}$ ditolak dan $\mathrm{H}_{\mathrm{a}}$ diterima karena $f_{\text {hitung }}>f_{\text {tabel. }}$. Hal ini menunjukkan bahwa terdapat pengaruh yang sangat signifikan antara Kecerdasan Intelektual $\left(X_{1}\right)$, Kecerdasan Emosional $\left(X_{2}\right)$ dan Kecerdasan
\end{abstract}


Spiritual $\left(\mathrm{X}_{3}\right)$ terhadap Kinerja Karyawan $(\mathrm{Y})$ pada PT Perusahaan Gas Negara (Persero) Tbk Sales Area Bekasi

\section{Kata Kunci: Kecerdasan Intelektual $\left(X_{1}\right)$, Kecerdasan Emosional $\left(X_{2}\right)$ dan Kecerdasan Spiritual $\left(\mathrm{X}_{3}\right)$, dan Kinerja Karyawan $(\mathrm{Y})$}

\section{Pendahuluan}

Dewasa ini persaingan di dunia usaha semakin meningkat tajam. Penemuanpenemuan baru, teknologi yang semakin canggih serta cara pemasaran yang semakin kreatif menuntut perusahaan untuk dapat mengambil keputusan yang tepat dan efisien dalam hal strategis. Keputusan tersebut menyangkut keputusan di dalam semua bidang fungsional. Peran manajemen sangat diperlukan agar tujuan dari organisasi dapat dicapai secara efektif dan efisien. Efektif menurut Peter F. Drucker adalah "mengerjakan pekerjaan yang benar" sedangkan efisian adalah "mengerjakan pekerjaan dengan benar" (Sule, 2008). Agar hal ini dapat terwujud manajemen perlu mengelola fungsi-fungsi manajemennya, terutama bagaimana mengelola sumber daya manusia sehingga meningkatkan efisiensi dan

efektivitas kerja agar organisasi tetap eksis dan mampu berkompetisi.

Kinerja karyawan (prestasi kerja) adalah hasil kerja secara kualitas dan kuantitas yang dicapai oleh seorang karyawan dalam melaksanakan tugasnya sesuai dengan tanggung jawab yang diberikan kepadanya (Mangkunegara, 2012).

Kinerja seseorang dapat dipengaruhi oleh berbagai faktor, baik faktor eksternal maupun internal dari karyawan tersebut. Simamora dalam Mangkunegara (2012) mengatakan bahwa kinerja pada umumnya dipengaruhi oleh tiga faktor, yaitu (a) faktor individual (kemampuan dan keahlian, latar belakang, dan demografi), (b) faktor psikologis (persepsi, attitude, personality, pembelajaran, dan motivasi), (c) faktor organisasi (sumber daya, kepemimpinan, penghargaan, struktur dan job design). Pada beberapa dekade terakhir ada beberapa faktor yang juga mempengaruhi kinerja karyawan, yaitu perasaan emosional di tempat kerja, khususnya emotional intelligence (kecerdasan emosional), kecerdasan intelektual dan kecerdasan spiritual yang saat ini menjadi topik perbincangan yang hangat di kalangan manajemen (Alam, 2007).

Penelitian Hardiat (2016) meneliti Pengaruh Kecerdasan Emosional, Kecerdasan Intelektual dan Kecerdasan Spiritual terhadap Kinerja Karyawan Marketing PT Nasmoco Bahana Motor mengatakan ada pengaruh secara signifikan terhadap kinerja karyawan.

Daniel Goleman (1996) dalam penelitian Hidayati (2013) mengatakan bahwa kecerdasan emosional menyumbang $80 \%$ dari faktor penentu kesuskesan seseorang sedangkan $20 \%$ yang lain ditentukan oleh IQ (Intelligence Quotient). Kecerdasan emosional tersebut antara lain meliputi rasa empati, mengungkapkan dan memahami perasaan, kemampuan mengelola diri sendiri, 
kemampuan menyesuaikan diri, kemampuan menyelesaikan maslah antar pirbadi, membina hubungan dengan orang lain, serta melakukan pemikiran yang tenang tanpa terbawa emosi, sehingga kecerdasan emosional sangat diperlukan untuk sukses dalam bekerja dan menghasilkan kinerja yang menonjol dalam pekerjaan.

Sudah tidak dapat dipungkiri bahwa kesuksesan dan keberhasilan seseorang tidak hanya ditentukan oleh kecerdasan intelektual (IQ) saja tetapi keberhasilan dan kesuksesan atau kinerja seseorang juga dipengaruhi oleh kecerdasan emosional (EQ) dan Kecerdasan Spiritual (SQ). Sa'baniah (2015) mengatakan bahwa suatu hal yang mempengaruhi individu dalam bekerja, baik itu terkait motivasi, kecerdasan, sikap terhadap pekerjaan, budaya organisasi dan kepemimpinan adalah religiusitas.

PT Perusahaan Gas Negara (Persero) Tbk (PGN) merupakan salah satu Perusahaan BUMN besar di Indonesia. Perusahaan ini bergerak di bidang infrastruktur dan pendistribusian gas bumi. Besarnya permintaan gas pada masa sekarang ini membuat peluang pasar PGN sangat besar, sehingga menuntut perusahaan untuk dapat bertumbuh menjadi lebih baik sesuai dengan visi perusahaan yaitu "Menjadi Perusahaan Kelas Dunia di Bidang Energi".

Pada Indeks Kepuasan Pelanggan Tahun 2016 yang dilakukan oleh pihak ekternal terhadap pelanggan $\mathrm{PGN}$, didapatkan data bahwa dari skala $1-6$ Indeks Kepuasan
Pelanggan sebesar 5,37 dengan nilai Indeks Loyalitas Pelanggan sebesar 5,59.

\section{Gambar 1}

Customer Loyalty Indeks Area Bekasi Tahun 2016

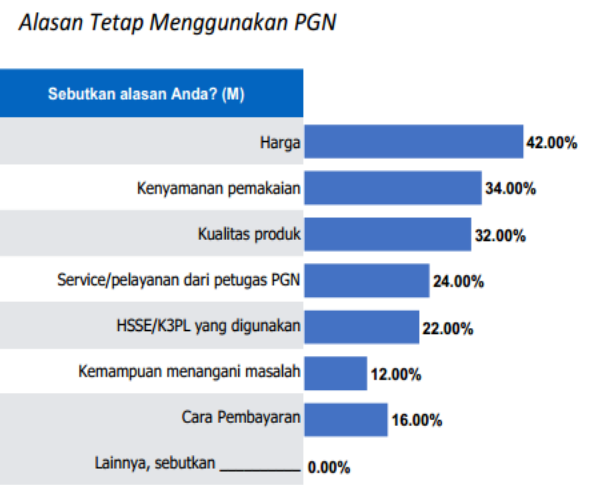

Dari data tersebut diatas, dapat terlihat bahwa loyalitas pelanggan PGN memiliki nilai besar $(32 \%-42 \%)$ hanya pada hal-hal yang terkait dengan produk, seperti harga produk, kenyamanan pemakaian produk dan kualitas produk. Sementara untuk hal-hal yang terkait dengan pelayanan pelanggan memiliki nilai yang rendah (16\% - 24\%). Maka dapat disimpulkan bahwa pada dasarnya pelanggan puas terhadap kinerja pelayanan dari karyawan PGN namun mempunyai loyalitas yang kurang sebagai pelanggan PGN. Jika hal ini tidak segera ditanggulangi, tidak tertutup kemungkinan para pelanggan PGN akan beralih kepada competitor PGN yang menawarkan produk dengan kualitas yang sama namun dengan pelayanan yang lebih baik. Untuk itu apabila PGN ingin agar para pelanggannya tetap memakai setia memakai produknya, hal yang perlu ditingkatkan adalah pelayanan / servis terhadap pelanggan sehingga servis dapat dapat mempunyai nilai yang setara dengan produk PGN. Agar pelayanan terhadap pelanggan dapat meningkat 
maka sumber daya manusia / kinerja karyawan perlu ditingkatkan.

Berdasarkan uraian diatas, penulis memandang perlunya melakukan penelitian tentang ada tidaknya pengaruh Kecerdasan Intelejensi, Kecerdasan Emosional dan Kecerdasan Spiritual terhadap kemampuan karyawan di tempat kerja.

Penelitian ini bertujuan untuk mengetahui pengaruh kecerdasan intelektual (IQ), kecerdasan emosi (EQ), kecerdasan spiritual (SQ) terhadap kinerja karyawan dan faktor kecerdasan mana yang lebih berpengaruh.

Penulisan skripsi ini mempunyai dua kegunaan, yaitu yang pertama kegunaan teoritis, yaitu sebagai tambahan referensi untuk mengembangkan ilmu pengetahuan khususnya bidang manajemen sumber daya manusia. Sedangkan yang kedua kegunaan praktis, yaitu memberikan informasi kepada perusahaan bagaimana pengaruh dari IQ, EQ dan SQ untuk meningkatkan kinerja karyawan.

Kecerdasan intelektual merupakan kemampuan intelektual, analisa, logika dan rasio. Kecerdasan ini merupakan kecerdasan untuk menerima, menyimpan dan mengelola informasi menjadi fakta (Widodo, 2012). Kecerdasan intelektual lazim disebut dengan intelegensi. Menurut Anastasi (1997) dalam Hardiat (2016) disebutkan bahwa intelegeni bukanlah kemampuan tunggal dan seragam tetapi merupakan komposit dari berbagai fungsi. Istilah ini umumnya digunakan untuk mencakup gabungan kemampuan-kemampuan yang diperlukan untuk bertahan dan maju dalam budaya tertentu (Trihandini, 2005).
Robbins (2014) juga menyebutkan bahwa kecerdasan intelektual adalah kemampuan yang dibutuhkan untuk melakukan berbagai aktifitas berfikir, memecahkan masalah dan mampu menyimpulkan dan mengelola informasi menjadi nyata.

Menurut Robbins (2014) mengatakan bahwa dalam kecerdasan intelektual terdapat tujuh dimensi seperti di bawah ini, yaitu kecerdasan angka, pemahaman verbal, kecepatan persepsi, penalaran induktif, penalaran dedukatif, visualisasi spasial, daya ingat.

\section{Gambar 2}

Dimensi Kecerdasan Spiritual

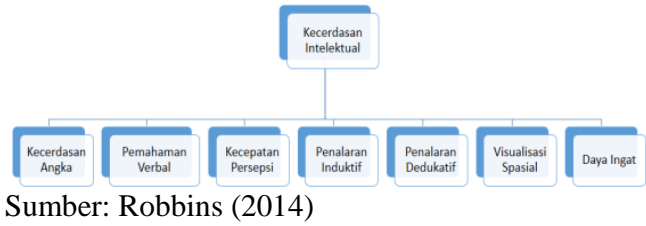

Selama ini banyak orang menganggap bahwa jika seseorang memiliki tingkat kecerdasan intelektual yang tinggi, maka orang tersebut memiliki peluang untuk meraih kesuksesan yang lebih besar dibandingkan dengan orang yang memiliki Intelektual rendah. Menurut Robins (2008) dalam Hardiat (2016) mengatakan kecerdasan intelektual adalah kemampuan yang dibutuhkan untuk melakukan berbagai aktifitas berfikir, memecahkan masalah dan mampu menyimpulkan dan mengelola informasi menjadi nyata.

Goleman (2015) mengemukakan lima kecakapan dasar dalam kecerdasan emosi, yaitu Self Awareness, Self Management, 
Motivation, Social Awareness, dan Relationship Management.

Gambar 3

Dimensi Kecerdasan Emosional

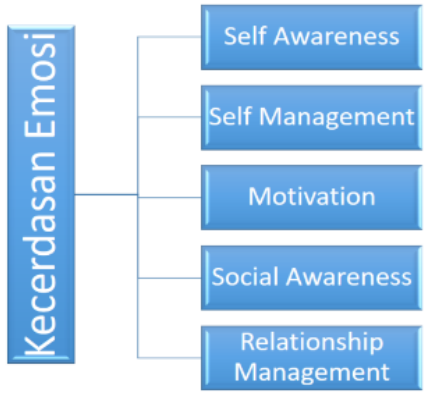

Sumber: Goleman (2015)

Sebuah penelitian pada sekitar 42.000 orang di 36 negara mengungkapkan hubungan positif antar kecerdasan emosional dan kesuksesan dalam kehidupan pribadi dan pekerjaan (Stein dan Book, 2002) dalam Moniaga (2012). Ini menunjukkan bahwa seorang karyawan juga bisa berhasil, jika di dalam diri mereka terbentuk nilai-nilai EQ yang tinggi.

Eckersley (2000) mendefinisikan kecerdasan spiritual sebagai perasaan instuisi yang dalam terhadap keterhubungan dengan dunia luas di dalam hidup manusia. Konsep mengenai kecerdasan spiritual dalam hubungannya dengan dunia kerja, menurut Ashmos dan Duchon (2000, dalam Trihandini 2005) terdapat tiga komponen yaitu kecerdasan spritual sebagai nilai kehidupan dari dalam diri, sebagai kerja yang memiliki arti dan komunitas.

Sukidi (2002, dalam Handayani, 2014) mengemukakan tentang nilai dari kecerdasan spiritual berdasarkan komponen - komponen dalam kecerdasan spiritual (SQ) yang banyak dibutuhkan dalam dunia bisnis. Komponen yan pertama yaitu jujur yang merupakan suatu kunci dalam dunia bisnis dengan berkata benar dan konsisten akan kebenaran. Ini merupakan hukum spiritual dalam dunia usaha. Selain kejujuran, keterbukaan juga menjadi hukum alam yang ada dalam dunia usaha.

Gambar 4

Dimensi Kecerdasan Spiritual

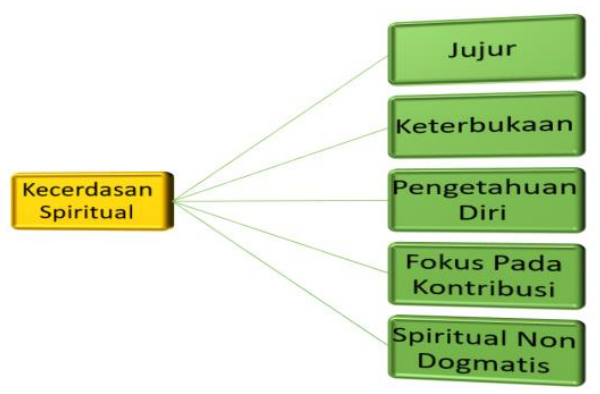

Sumber: Sukidi (2002)

Kinerja merupakan sebuah kata dalam Bahasa Indonesia yang berasal dari kata dasar 'Kerja' yang merjemahkan kata dari bahasa asing yaitu prestasi. Bisa pula diartikan sebagai hasil kerja. Kinerja (Prestasi Kerja) adalah hasil kerja secara kualitas dan kuantitas yang dicapai oleh seorang pegawai dalam melaksanakan tugasnya sesuai dengan tanggung jawab yang diberikan kepadanya (Hasibuan, 2005).

Menurut Wirawan (2015) dimensi kinerja adalah unsur-unsur dalam pekerjaan yang menunjukkan kinerja. Untuk mengukur kinerja, dimensi-dimensi kinerja dikembangkan menajdi indikator kinerja guna mengembangkan instrumen evaluasi kinerja yang kemudian digunakan untuk mengukur kinerja seorang pegawai. Pengembangan dimensi dan indikator kinerja dilaksanakan melalui analisis pekerjaan. 
Secara umum dimensi kinerja dapat dikelompokkan menjadi tiga jenis, yaitu hasil kerja, perilaku kerja dan sifat pribadi.

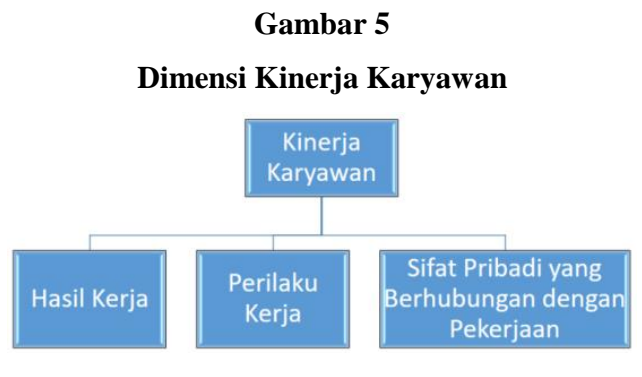

Sumber: Wirawan (2015)

Dalam melakukan penelitian ini maka penulis mengacu pada penelitian sebelumnya. Yang pertama yaitu oleh Pingkan Moniaga Tahun 2012 yang melakukan analisa pengaruh analisa pengaruh kecerdasan intelektual, kecerdasan emosional dan kecerdasan spiritual terhadap kinerja karyawan PT Bank Sulut Kantor Pusat dengan diperoleh variabel kecerdasan emosional (EQ) tidak signifikan, variabel kecerdasan intelektual (IQ) dan variabel kecerdasan spiritual signifikan. Dan terdapat pengaruh varibel lain yang tidak dimasukkan dalam model penelitian ini.

Caludia Angelika Wijaya pada Tahun 2014 melakukan analisa pengaruh kecerdasan intelektual, kecerdasan emosional dan kecerdasan spiritual terhadap kinerja karyawan di hotel "X"), dengan hasil analisa kecerdasan intelektual, kecerdasan emosional dan kecerdasan spiritual secara parsial dan signifikan mempengaruhi kinerja karyawan.

Hardiat pada tahun 2016 melakukan analisa pengaruh analisa pengaruh kecerdasan intelektual, kecerdasan emosional dan kecerdasan spiritual terhadap kinerja karyawan marketing PT Nasmoco Bahana Motor di Kota Yogyakarta dan diperoleh pengaruh kecerdasan emosional, kecerdasan intelektual dan kecerdasan spiritual signifikan terhadap kinerja karyawan.

Kerangka pemikiran sebagai dasar penelitian dengan gambaran di bawah ini.

Gambar 6

Kerangka Pemikiran Hubungan Antar Variabel

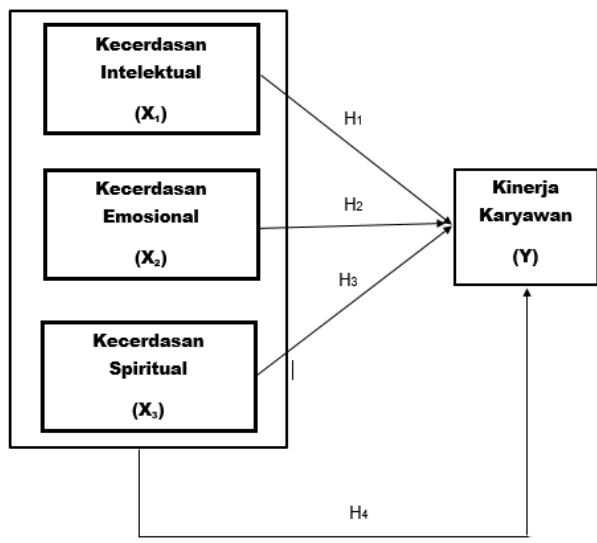

Keterangan:

Variabel $\mathrm{X}_{1}$ : Kecerdasan Intelektual

Variabel $\mathrm{X}_{2}$ :Kercerdasan Emosional

Variabel $\mathrm{X}_{3}$ : Kecerdasan Spiritual

Variabel Y : Kinerja Karyawan

\section{Metodologi}

Metode penelitian yang penulis gunakan dalam penelitian ini adalah kausal yang tujuannya mengetahui hubungan sebab akibat antara variable Kecerdasan Intelektual $\left(\mathrm{X}_{1}\right)$, variable Kecerdasan Emosional $\left(\mathrm{X}_{2}\right)$, Kecerdasan Spiritual $\left(\mathrm{X}_{3}\right)$ dengan variable Kinerja Karyawan (Y).

Variabel bebas yang digunakan (X) adalah variabel yang berdiri sendiri dan tidak dipengaruhi oleh variabel lainnya.

Tabel 1

Dimensi dan Indikator Kecerdasan Intelektual 


\begin{tabular}{|c|c|c|}
\hline \multicolumn{3}{|r|}{ Indikator } \\
\hline \multirow{7}{*}{ 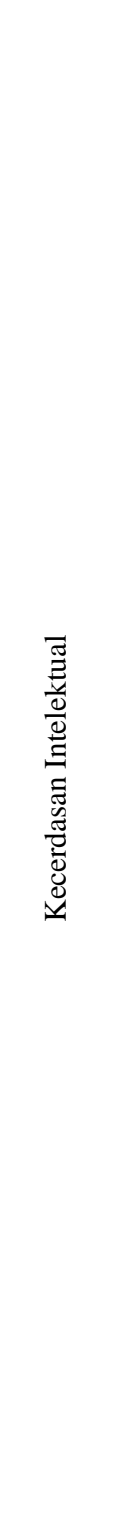 } & $\begin{array}{l}\text { Kecerdasan } \\
\text { Angka }\end{array}$ & $\begin{array}{l}\text { Mampu } \\
\text { menghitung } \\
\text { dengan cepat } \\
\text { dan tepat }\end{array}$ \\
\hline & $\begin{array}{l}\text { Pemahaman } \\
\text { Verbal }\end{array}$ & $\begin{array}{l}\text { Mampu } \\
\text { memahami apa } \\
\text { yang dibaca dan } \\
\text { didengar }\end{array}$ \\
\hline & $\begin{array}{l}\text { Kecepatan } \\
\text { Persepsi }\end{array}$ & $\begin{array}{lr}\text { Mampu } & \\
\text { mengenali } & \\
\text { kemiripan } & \text { dan } \\
\text { beda } & \text { visual } \\
\text { dengan } & \text { cepat } \\
\text { dan tepat } & \end{array}$ \\
\hline & $\begin{array}{l}\text { Penalaran } \\
\text { Induktif }\end{array}$ & $\begin{array}{l}\text { Mampu } \\
\text { menganalisa } \\
\text { urutan logis } \\
\text { masalah dan } \\
\text { memecahkan } \\
\text { masalah }\end{array}$ \\
\hline & $\begin{array}{l}\text { Penalaran } \\
\text { Deduktif }\end{array}$ & $\begin{array}{l}\text { Mampu } \\
\text { menggunakan } \\
\text { logika dan } \\
\text { menilai } \\
\text { implikasi dari } \\
\text { suatu argument }\end{array}$ \\
\hline & $\begin{array}{l}\text { Visualisasi } \\
\text { Spasial }\end{array}$ & $\begin{array}{l}\text { Mampu } \\
\text { membayangkan } \\
\text { perubahan dari } \\
\text { suatu objek jika } \\
\text { dilakukan } \\
\text { perubahan }\end{array}$ \\
\hline & Daya Ingat & $\begin{array}{l}\text { Mampu } \\
\text { mengenang atau } \\
\text { mengingat } \\
\text { kejadian dimasa } \\
\text { lalu }\end{array}$ \\
\hline
\end{tabular}

Sumber: Robbins (2014)

\section{Variabel bebas $\left(\mathrm{X}_{2}\right)$ Kecerdasan}

Emosional pada penelitian ini adalah (Goleman, 2015), yaitu self awareness, self management, motivation, social awareness dan relation management

Tabel 2

Dimensi dan Indikator Kecerdasan Emosional

\begin{tabular}{|c|c|c|}
\hline Variabel & Dimensi & Indikator \\
\hline 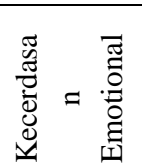 & $\begin{array}{l}\text { Self } \\
\text { Awareness }\end{array}$ & $\begin{array}{l}\text { Mampu mengetahui } \\
\text { perasaan dalam dirinya } \\
\text { dan efekny terhadap diri } \\
\text { sendiri }\end{array}$ \\
\hline
\end{tabular}

\begin{tabular}{|c|c|}
\hline & $\begin{array}{l}\text { Memiliki kepercayaan } \\
\text { diri yang tinggi }\end{array}$ \\
\hline \multirow[t]{2}{*}{$\begin{array}{l}\text { Self } \\
\text { Management }\end{array}$} & $\begin{array}{lr}\text { Dapat } & \text { mengekpresikan } \\
\text { dan } & \text { mengendalikan } \\
\text { emosi } & \end{array}$ \\
\hline & $\begin{array}{l}\text { Memiliki kepekaan } \\
\text { terhadap kata hati dan } \\
\text { digunakan dalam } \\
\text { hubungan dan tindakan } \\
\text { sehari-hari }\end{array}$ \\
\hline \multirow[t]{3}{*}{ Motivation } & $\begin{array}{l}\text { Mampu bertahan } \\
\text { menghadapi kegagalan }\end{array}$ \\
\hline & $\begin{array}{l}\text { Mampu mengambil } \\
\text { inisiatif }\end{array}$ \\
\hline & $\begin{array}{l}\text { Mampu bertindak } \\
\text { secara efektif }\end{array}$ \\
\hline \multirow[t]{4}{*}{$\begin{array}{l}\text { Social } \\
\text { Awareness } \\
\text { (Empati) }\end{array}$} & $\begin{array}{l}\text { Mampu merasakan apa } \\
\text { yang dirasakan oleh } \\
\text { orang lain }\end{array}$ \\
\hline & $\begin{array}{l}\text { Mampu memahami } \\
\text { perspektif orang lain }\end{array}$ \\
\hline & $\begin{array}{lr}\text { Mampu } & \text { menimbulkan } \\
\text { hubungan } & \text { saling } \\
\text { percaya } & \\
\end{array}$ \\
\hline & $\begin{array}{l}\text { Mampu menyelaraskan } \\
\text { diri dengan berbagai } \\
\text { tipe individu }\end{array}$ \\
\hline \multirow[t]{4}{*}{$\begin{array}{l}\text { Relationship } \\
\text { Management }\end{array}$} & $\begin{array}{lr}\text { Mampu menangani } \\
\text { emosi } \\
\text { berhubungan } \\
\text { orang lain }\end{array}$ \\
\hline & $\begin{array}{l}\text { Dapat menciptakan dan } \\
\text { mempertahankan } \\
\text { hubungan dengan orang } \\
\text { lain }\end{array}$ \\
\hline & $\begin{array}{l}\text { Bisa mempengaruhi, } \\
\text { memimpin, } \\
\text { bermusyawarah dan } \\
\text { menyelesaikan } \\
\text { perselisihan }\end{array}$ \\
\hline & $\begin{array}{l}\text { Dapat bekerja sama } \\
\text { dalam tim }\end{array}$ \\
\hline
\end{tabular}

\section{Goleman (2015)}

Variabel bebas $\left(\mathrm{X}_{3}\right)$ adalah Kecerdasan Spiritual yang digunakan pada penelitian ini adalah jujur, keterbukaan, pengetahuan diri, fokus pada kontribusi dan spiritual non dogmatis

Tabel 3

Dimensi dan Indikator Kecerdasan Spiritual 


\begin{tabular}{|c|c|c|}
\hline Variabel & Dimensi & Indikator \\
\hline \multirow{12}{*}{ 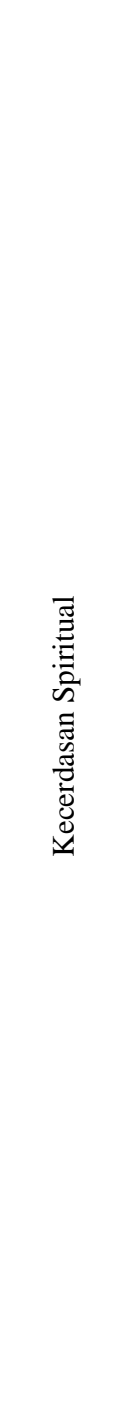 } & \multirow[t]{2}{*}{ Jujur } & $\begin{array}{ll}\text { Mampu } & \text { berkata } \\
\text { sesuai } & \text { dengan } \\
\text { kebenaran } & \\
\end{array}$ \\
\hline & & $\begin{array}{ll}\text { Konsisten } & \text { dalam } \\
\text { bertindak } & \end{array}$ \\
\hline & \multirow{2}{*}{$\begin{array}{l}\text { Keterbuka } \\
\text { an }\end{array}$} & Mampu bersikap adil \\
\hline & & $\begin{array}{l}\text { Selalu berpartisipasi } \\
\text { di jalan yang baik }\end{array}$ \\
\hline & \multirow[t]{2}{*}{$\begin{array}{l}\text { Pengetahu } \\
\text { an Diri }\end{array}$} & $\begin{array}{l}\text { Memiliki } \\
\text { pengetahuan yang } \\
\text { luas }\end{array}$ \\
\hline & & $\begin{array}{l}\text { Mampu memahami } \\
\text { barang atau } \\
\text { pengetahuan baru }\end{array}$ \\
\hline & \multirow[t]{2}{*}{$\begin{array}{l}\text { Fokus } \\
\text { Pada } \\
\text { Kontribusi }\end{array}$} & $\begin{array}{l}\text { Memiliki keinginan } \\
\text { untuk } \\
\text { menyumbangkan } \\
\text { kebaikan pada } \\
\text { lingkungan }\end{array}$ \\
\hline & & $\begin{array}{lr}\text { Menjaga } & \text { lingkungan } \\
\text { sekitar agar lebih } \\
\text { nyaman }\end{array}$ \\
\hline & \multirow{4}{*}{$\begin{array}{l}\text { Spiritual } \\
\text { Non } \\
\text { Dogmatis }\end{array}$} & $\begin{array}{ll}\text { Dapat } & \text { bersikap } \\
\text { fleksibel } & \end{array}$ \\
\hline & & $\begin{array}{l}\text { Memiliki kesadaran } \\
\text { yang tinggi }\end{array}$ \\
\hline & & $\begin{array}{l}\text { Mampu menghadapi } \\
\text { dan memanfaatkan } \\
\text { penderitaan }\end{array}$ \\
\hline & & $\begin{array}{l}\text { Memiliki kualitas } \\
\text { hidup yang diilhami } \\
\text { oleh visi dan nilai }\end{array}$ \\
\hline
\end{tabular}

Sumber: Sukidi (2002)

Variabel terikat $(\mathrm{Y})$ dalam penelitian ini dalah kinerja karyawan adalah:

Tabel 4

Dimensi dan Indikator Kinerja Karyawan

\begin{tabular}{|c|c|c|}
\hline Variabel & Dimensi & Indikator \\
\hline \multirow{3}{*}{ 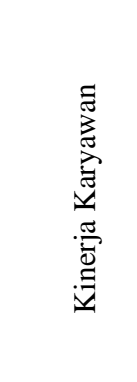 } & \multirow{3}{*}{$\begin{array}{l}\text { Hasil } \\
\text { Kerja }\end{array}$} & $\begin{array}{c}\text { Kuantitas Hasil } \\
\text { Kerja }\end{array}$ \\
\hline & & $\begin{array}{c}\text { Kualitas Hasil } \\
\text { Kerja }\end{array}$ \\
\hline & & $\begin{array}{c}\text { Ketepatan } \\
\text { Dalam } \\
\text { Melaksanakan } \\
\text { Pekerjaan }\end{array}$ \\
\hline
\end{tabular}

\begin{tabular}{|c|c|c|}
\hline \multirow{1}{*}{$\begin{array}{c}\text { Perilaku } \\
\text { Kerja }\end{array}$} & Kerjasama \\
\cline { 3 - 3 } & & $\begin{array}{c}\text { Memanfaatkan } \\
\text { Waktu }\end{array}$ \\
\cline { 3 - 3 } & \begin{tabular}{c} 
Sifat \\
Pribadi \\
Yang Ada \\
Hubungan \\
nya \\
Dengan \\
\cline { 3 - 3 }
\end{tabular} & Pengetahuan \\
\cline { 3 - 3 } & Keterampilan \\
\hline
\end{tabular}

Sumber: Wirawan (2015)

\section{Pembahasan}

Objek penelitian ini adalah PT PGN (Persero) Tbk Area Bekasi yang terletak di Jalan Boulevard Selatan, Ruko Sinpasa Blok A, No. 11-12, Sumarecon Bekasi, 17142.

Teknik pengumpulan data yang paling pokok dilakukdan dalam penelitian ini adalah survey dan pengumpulan data. Menurut Indriantoro dan Supomo mengemukakan pengertian dari metode survey, "Merupakan metode pengumpulan data primer berdasarkan komunikasi antara penelitian dengan responden"

Skala Likert digunakan untuk mengukur sikap, pendapat dan perseptsi seseorang atau kelompok tentang sosial (Sugiyono, 2016). Pada penelitian ini, peneliti menggunakan Skala Likert dalam penyunsunan kuesioner.

Tabel 6

Skala Likert 5 Poin

\begin{tabular}{|c|c|}
\hline Jawaban & Nilai Bobot \\
\hline Sangat Sesuai & 5 \\
\hline Sesuai & 4 \\
\hline Ragu-ragu & 3 \\
\hline
\end{tabular}




\begin{tabular}{|c|c|}
\hline Tidak Sesuai & 2 \\
\hline Sangat Tidak Sesuai & 1 \\
\hline
\end{tabular}

Sumber : Sugiyono

Penulis melakukan wawancara kepada karyawan untuk memenuhi data yang dibutuhkan yang berkaiatan dengan penelitian penulis.

Populasi menurut Supranto (2016), adalah kumpulan dari seluruh elemen sejenis tetapi dapat dibedakan satu sama lain karena karakteristiknya. Dalam penelitian ini populasi yang dimaksud adalah karyawan di PT PGN (Persero) Tbk Area Bekasi mencakup penjualan dan operasi yang berjumlah 50 orang.

Sampel menurut Supranto (2016) adalah sebagian dari populoasi. Jika $n$ adalah banyaknya elemen sampel dan $N$ adalah banyaknya populasi, maka $n<N$ ( $n$ lebih kecil dari $N$ ). Istilah lain dari sampel adalah contoh. Dari populasi yang ada, ukuran sampel minimum diperoleh dengan menggunakan rumus Slovin dalam Umar (2010).

Rumus Slovin:

$$
n=\frac{N}{1+N(e)^{2}}
$$

Keterangan :

$\mathrm{N}=$ Ukuran Populasi

$\mathrm{N}=$ Ukuran Sampel

$\mathrm{E}=$ Persen kelonggaran ketidakpastian karena kesalahan

Pengambilan sampel yang masih ditolerir, maksimum $5 \%$. Dari rumus di atas dapat di tentukan ukuran sampel minimum:

$$
n=\frac{50}{1+50(0,05)^{2}}=44,4
$$

Regresi linier berganda adalah alat untuk mengukur besarnya pengaruh variabel bebas yang lebih dari satu terhadap variabel terikat. Persamaan regresi linier berganda adalah :

$$
\hat{\mathrm{Y}}=a+b_{1} X_{1}+b_{2} X_{2}+b_{3} X_{3}+\cdots
$$

Keterangan :

$\hat{\mathrm{Y}}=$ Produktivitas karyawan

$\mathrm{a}=$ Konstanta

$\mathrm{b}_{1}=$ Koefisien regresi variabel $\mathrm{x} 1$

$\mathrm{b}_{2}=$ Koefisien regresi variabel $\mathrm{x} 2$

$\mathrm{b}_{3}=$ Koefisien regresi variabel $\mathrm{x} 3$

$\mathrm{x}_{1}=$ Gaya Kepemimpinan

$\mathrm{x}_{2}=$ Motivasi

$\mathrm{x}_{3}=$ Lingkungan Kerja

$\mathrm{n}=$ jumlah sampel

Responden yang menjadi objek penelitian ini adalah Karyawan PGN Area Bekasi. Adapun data responden dilihat dari jenis kelamin, umur, pendidikan dan masa kerja.

Karakteristik Responden Berdasarkan jenis kelamin, umur, pendidikan dan mas kerja.

Tabel 7

Karakteristik Responden Berdasarkan Jenis Kelamin

\begin{tabular}{|l|r|r|r|}
\hline Jenis & \multicolumn{1}{|c|}{$\begin{array}{c}\text { Frequ } \\
\text { ency }\end{array}$} & \multicolumn{1}{c|}{ Percent } & \multicolumn{1}{c|}{$\begin{array}{c}\text { Valid } \\
\text { Percent }\end{array}$} \\
\hline Laki-laki & 28 & 63.6 & 63.6 \\
\hline Perempuan & 16 & 36.4 & 36.4 \\
\hline Total & 44 & 100.0 & 100.0 \\
\hline
\end{tabular}

Sumber : Output Data Pengolahan SPSS 22

Tabel 8

Karakteristik Responden Berdasarkan Umur Responden

\begin{tabular}{|r|r|r|r|}
\hline Tahun & Frequency & Percent & \multicolumn{1}{|c|}{$\begin{array}{c}\text { Valid } \\
\text { Percent }\end{array}$} \\
\hline $20-29$ & 4 & 9.1 & 9.1 \\
\hline $30-39$ & 30 & 68.2 & 68.2 \\
\hline $40-49$ & 7 & 15.9 & 15.9 \\
\hline
\end{tabular}




\begin{tabular}{|l|r|r|r|}
\hline $50-59$ & 3 & 6.8 & 6.8 \\
\hline Total & 44 & 100.0 & 100.0 \\
\hline
\end{tabular}

Sumber : Output Data Pengolahan SPSS 22

Tabel 9

Karakteristik Responden Berdasarkan Pendidikan

\begin{tabular}{|l|r|r|r|}
\hline & $\begin{array}{c}\text { Freque } \\
\text { ncy }\end{array}$ & Percent & $\begin{array}{c}\text { Valid } \\
\text { Percent }\end{array}$ \\
\hline SMP & 1 & 2.3 & 2.3 \\
\hline SMA / Sdrjt & 17 & 38.6 & 38.6 \\
\hline Diploma 3 & 8 & 18.2 & 18.2 \\
\hline Strata 1 & 16 & 36.4 & 36.4 \\
\hline Strata 2 & 2 & 4.5 & 4.5 \\
\hline Total & 44 & 100.0 & 100.0 \\
\hline
\end{tabular}

Sumber : Output Data Pengolahan SPSS 22

Tabel 10

Karakteristik Responden Berdasarkan Masa Kerja

\begin{tabular}{|l|r|r|r|}
\hline Tahun & Frequency & Percent & \multicolumn{1}{c|}{$\begin{array}{c}\text { Valid } \\
\text { Percent }\end{array}$} \\
\hline $1-5$ & 20 & 45.5 & 45.5 \\
\hline $6-10$ & 19 & 43.2 & 43.2 \\
\hline $11-15$ & 2 & 4.5 & 4.5 \\
\hline $26-30$ & 3 & 6.8 & 6.8 \\
\hline Total & 44 & 100.0 & 100.0 \\
\hline
\end{tabular}

Sumber : Output Data Pengolahan SPSS 22

Untuk memperoleh data yang diperlukan dalam penulisan skripsi ini, penulis mengajukan seperangkat kuesioner kepada para responden yang berjumlah 44 orang. Kuesioner tersebut kemudian diteliti lebih lanjut dengan menggunakan perhitungan metode SPSS 22 for windows.

Kuesioner yang diajukan terdiri dari sejumlah pertanyaan dan pertanyaan yang mewakili empat variabel sesuai dengan jumlah variabel yang ada. Keempat instrument penelitian yang berbentuk kuisioner itu adalah tentang kecerdasan intelektual, kecerdasan emosional, kecerdasan spiritual dan kinerja karyawan.

Berdasarkan perhitungan dengan olahan data statistik SPSS 22 for windows yang terlihat pada lampiran, diperoleh hasil-hasil reliabilitas untuk masing-masing variabel sebagai berikut:

Tabel 11

Hasil Reliabilitas Kuesioner Variabel Kecerdasan Intelektual $\left(\mathbf{X}_{1}\right)$

\begin{tabular}{|r|r|}
\hline Cronbach's Alpha & N of Items \\
\hline .699 & 10 \\
\hline
\end{tabular}

Tabel 12

Hasil Reliabilitas Kuesioner Variabel Kecerdasan Emosional $\left(\mathbf{X}_{2}\right)$

\begin{tabular}{|r|r|}
\hline Cronbach's Alpha & N of Items \\
\hline .880 & 18 \\
\hline
\end{tabular}

Tabel 13

Hasil Reliabilitas Kuesioner Variabel Kecerdasan Spiritual $\left(\mathbf{X}_{3}\right)$

\begin{tabular}{|r|r|}
\hline Cronbach's Alpha & \multicolumn{1}{|l|}{ N of Items } \\
\hline .785 & 13 \\
\hline
\end{tabular}

Sumber : Output Data Pengolahan SPSS 22

Tabel 14

Hasil Reliabilitas Kuesioner Variabel Kinerja Karyawan (Y)

\begin{tabular}{|r|r|}
\hline Cronbach's Alpha & \multicolumn{1}{|l|}{ N of Items } \\
\hline .756 & 12 \\
\hline
\end{tabular}

Sumber : Output Data Pengolahan SPSS 22 
Dari hasil analisis di atas, diperoleh koefisien reliabilitas Alpha Cronbach sebesar 0.756 Dengan hasil tersebut maka bisa dikatakan bahwa data tersebut adalah reliabel, dengan angka menunjukan mendekati 1 dengan batas minimal 0.600

Berdasarkan tabel di atas uji normalitas diketahui adalah bahwa pada kolom variabel kecerdasan intelektual terdapat probabilitas signifikann 0,837 (Asymp. Sig. 2-tailed). Oleh karena itu Penempatan ini berdasarkan data olahan telah memenuhi syarat normalitas yaitu dengan nilai probabilitas $>0.05$, maka data variabel kecerdasan intelektual adalah normal, dan dapat digunakan dalam penelitian.

Pada kolom variabel kecerdasan emonsional probabilitas signifikan 0,252 (Asymp. Sig. 2-tailed). Oleh karena itu variabel motivasi berdasarkan data olahan telah memenuhi syarat normalitas yaitu dengan nilai probabilitas > 0.05 , maka data variabel kecerdasan emosional terdistribusi secara normal dan dapat digunakan dalam penelitian.

Sedangkan pada kolom variabel kecerdasan spiritual terdapat probabilitas signifikan 0,876 (Asymp. Sig. 2-tailed). Oleh karena itu variabel Lingkungan Kerja berdasarkan data olahan telah memenuhi syarat normalitas yaitu dengan nilai probabilitas > 0.05, maka variabel kecerdasan spiritual terdistribusi secara normal dan dapat digunakan dalam penelitian.

Dan pada kolom variabel kinerja karyawan terdapat probabilitas signifikan 0,586 (Asymp. Sig. 2-tailed). Oleh karena itu variabel kinerja karyawan berdasarkan data olahan telah memenuhi syarat normalitas yaitu dengan nilai probabilitas $>0.05$, maka variabel kinerja karyawan terdistribusi secara normal dan dapat digunakan dalam penelitiaan.

Regresi linier berganda digunakan untuk mengetahui pengaruh antara variable Kecerdasan Intelektual, Kecerdasan Emosional dan Kecerdasan Spiritual (independen) secara simultan atau bersama-sama terhadap Kinerja Karyawan (dependen). Dengan perhitungan regresi linier berganda dengan menggunakan SPSS (Statistical Package for the Social Science) versi 22.0, maka dihasilkan persamaan regresi berganda sebagai berikut :

$$
\begin{gathered}
\hat{\mathbf{Y}}=\mathbf{a}+\mathbf{b}_{\mathbf{1}} \mathbf{X}_{\mathbf{1}}+\mathbf{b}_{\mathbf{2}} \mathbf{X}_{\mathbf{2}}+\mathbf{b}_{\mathbf{3}} \mathbf{X}_{\mathbf{3}}+\boldsymbol{\epsilon} \\
\hat{\mathrm{Y}}=1,266+0,224 \mathrm{X}_{1}+0,349 \mathbf{X}_{2}+0,254 \mathbf{X}_{3}+€
\end{gathered}
$$

Dengan persamaan regresi berganda yang telah dihasilkan, maka dapat diperoleh hasil interpretasi sebagai berikut :

- Konstanta sebesar 1,266 menyatakan bahwa jika Kecerdasan Intelektual, Kecerdasan Emosional dan Kecerdasan Spiritual dianggap konstan atau nol, maka Kinerja Karyawan sebesar 1,266.

- Koefisien regresi Kecerdasan Intelektual sebesar 0,224 menyatakan setiap kenaikan Kecerdasan Intelektual sebesar 1 nilai maka Kinerja karyawan naik sebesar 0.224, dengan asumsi bahwa Kecerdasan Emosional dan Kecerdasan Spiritual tetap.

- Koefisien regresi Kecerdasan Emosional sebesar 0,349 menyatakan setiap kenaikan Kecerdasan Emosional sebesar 1 nilai maka Kinerja Karyawan naik sebesar 0,349 
dengan asumsi bahwa Kecerdasan Intelektual dan Kecerdasan Spiritual tetap.

- Koefisien regresi Kecerdasan Spiritual sebesar 0,254 menyatakan setiap kenaikan Kecerdasan Spiritual sebesar 1 nilai maka Kinerja Karyawan naik sebesar 0,254 dengan asumsi bahwa Kecerdasan Intelektual dan Kecerdasan Emosional tetap

Uji statistik t pada dasarnya menunjukkan seberapa jauh pengaruh suatu variabel penjelas/independen (X) secara individual dalam menerangkan variasi variabel dependen (Y). Berikut adalah hipotesis variabel Kecerdasan Intelektual, Kecerdasan Emosional dan Kecerdasan Spiritual terhadap Kinerja Karyawan individual (parsial), yaitu menunjukan bahwa Kecerdasan Intelektual, Kecerdasan Emosional dan Kecerdasan Spiritual memiliki pengaruh yang signifikan terhadap Kinerja Karyawan.

Uji simultan dimaksudkan untuk mengetahui apakah semua variabel bebas mempunyai pengaruh yang sama terhadap variabel terikat. Pengujian yang dilakukan menggunakan Uji F. Jika $F_{\text {hitung }}>F_{\text {tabel }}$ maka menolak hipotesis nol $\left(\mathrm{H}_{0}\right)$ dan menerima hipotesis alternatif $\left(\mathrm{H}_{\mathrm{a}}\right)$, yang berarti semua variabel bebas secara bersama-sama memiliki pengaruh terhadap variabel terikat.

Tabel 15

Hasil Uji Statistik F

\begin{tabular}{|c|c|c|c|c|c|}
\hline \multicolumn{6}{|c|}{ ANOVA $^{a}$} \\
\hline Model & $\begin{array}{l}\text { Sum of } \\
\text { Squares }\end{array}$ & Df & $\begin{array}{l}\text { Mean } \\
\text { Square }\end{array}$ & $\mathrm{F}$ & Sig. \\
\hline \begin{tabular}{|l|l}
1 & Regressi \\
on
\end{tabular} & 488.003 & 3 & 162.668 & 105.105 & .000 \\
\hline
\end{tabular}

\begin{tabular}{|l|r|r|r|l|l|}
\hline $\begin{array}{l}\text { Residua } \\
1\end{array}$ & 61.906 & 40 & 1.548 & & \\
\hline Total & 549.909 & 43 & & & \\
\hline a. Dependent Variable: Kinerja Karyawan & \\
\hline \\
b. Predictors: (Constant), Kecerdasan Spiritual, Kecerdasan \\
Intelektual, Kecerdasan Emotional \\
\hline
\end{tabular}

Sumber : Output Data Pengolahan SPSS 22

Dari hasil uji Anova atau F test pada table diatas didapat nilai $F_{\text {hitung }}$ sebesar 105,105 dan nilai $F_{\text {tabel }}$ dengan tingkat keyakinan $95 \%$ (menggunakan $\alpha=5 \%$ ), df1 (k-1) $3-1=2$, df2 ( $\mathrm{n}-\mathrm{k})$, sebesar $44-3=41$, dan diperoleh hasil $\mathrm{F}_{\text {tabel }}$ sebesar 3,23. Maka dapat dikatakan bahwa $F_{\text {hitung }}>F_{\text {tabel }}$ yaitu $105,105>3,23$. Dari table diatas diperoleh probabilitas (tingkat signifikansi) 0,000 . Oleh karena probabilitas 0,000 lebih kecil dari 0.05 , sehingga dari hasil yang diperoleh dapat dikatakan bahwa $\mathrm{H}_{03}$ ditolak dan $\mathrm{H}_{\mathrm{a} 3}$ diterima. Sehingga dapat diartikan bahwa model regresi dapat digunakan untuk memprediksi Kinerja Karyawan, dengan kata lain Kecerdasan Intelektual, Kecerdasan Emosional dan Kecerdasan Spiritual secara simultan (bersama-sama) berpengaruh terhadap Kinerja Karyawan.

Untuk mengetahui seberapa besar variabel Independen Kecerdasan Intelektual $\left(\mathrm{X}_{1}\right)$, Kecerdasan Emosional $\left(\mathrm{X}_{2}\right)$ dan Kecerdasan Spiritual $\left(\mathrm{X}_{3}\right)$ dapat menentukan hubungan dengan variabel dependen Kinerja Karyawan (Y) maka dapat dilihat pada tabel berikut :

Tabel 16

Koefisien Determinan

Model Summary ${ }^{b}$ 


\begin{tabular}{|l|r|r|r|r|}
\hline Model & \multicolumn{1}{c|}{$\mathrm{R}$} & R Square & $\begin{array}{l}\text { Adjusted } \\
\text { R Square }\end{array}$ & $\begin{array}{l}\text { Std. Error of } \\
\text { the Estimate }\end{array}$ \\
\hline 1 & $.942^{\mathrm{a}}$ & .887 & .879 & 1.244 \\
\hline
\end{tabular}

a. Predictors: (Constant), Kecerdasan Spiritual,

Kecerdasan Intelektual, Kecerdasan Emotional

b. Dependent Variable: Kinerja Karyawan

Sumber : Output Data Pengolahan SPSS 22

Berdasarkan hasil pengolahan data diatas dapat dilihat bahwa nilai koefisien determinasi yang sudah disesuaikan (R Square Adjusted) adalah sebesar 0.897 dengan kata lain 87,9\% variable dependen Kinerja Karyawan dipengaruhi oleh variabel independen Kecerdasan Intelektual, Kecerdasan Emosional da Kercerdasan Spiritual. Sisanya sebesar $12,1 \%$ dipengaruhi oleh variabel lain diluar variabel yang digunakan.

Pada kuesioner variabel kecerdasan intelektual terdapat nilai tertinggi yaitu saya mampu memahami SOP terkait pekerjaan saya. Pertanyaan ini termasuk dalam pemahaman verbal. Artinya mayoritas responden mempunyai kekuatan dalam pemahaman verbal di lingkungan kerja. Dalam pekerjaan migas, pemahaman dan kepatuhan terhadap SOP merupakan salah satu hal yg diutamakan dalam penerapan $\mathrm{K} 3$.

Mayoritas responden dalam variabel kecerdasan emosional memberikan respon setuju untuk pertanyaan saya mampu mengekspresikan perasaan yang saya alami tanpa mengurangi profesionalisme dalam bekerja. Pertanyaan ini masuk dalam kategori self management, sehingga dapat diartikan mayoritas responden dapat selalu berekspresi tanpa mengurangi profesionalisme yang secara langsung berpengaruh pada kinerja.

Salah satu pertanyaan dalam variabel kecerdasan sprititual yaitu saya melaksanakan apa yg sdh menjadi kesepakatan bersama yg merupakan dalam .. jujur. Artinya mayoritas responden mempunyai kekuatan spritual yg mempratekkan nilai jujur di lingkungan kerja. Dalam hal kesepakatan bersama artinya para karyawan mempunyai kinerja yg baik karena menjalankan pekerjaan sesuai kesepakatan bersama.

\section{Kesimpulan dan Saran}

Secara parsial Kecerdasan Intelektual $\left(\mathrm{X}_{1}\right)$ berpengaruh signifikan terhadap Kinerja Karyawan (Y). Hal ini di buktikan dengan nilai probabilitas signifikansi sebesar 0,009 yang lebih kecil dari $\alpha=0.05$ atau dengan $t_{\text {hitung }}>t_{\text {tabel }}$ $(2,764>2,019)$. Dengan demikian $\mathrm{H}_{\mathrm{a} 1}$ diterima dan $\mathrm{H}_{01}$ ditolak.

Secara parsial Kecerdasan Emosional $\left(\mathrm{X}_{2}\right)$ tidak berpengaruh signifikan terhadap Kinerja Karyawan (Y). Hal ini dibuktikan dengan nilai probabilitas signifikansi sebesar 0,000 yang lebih kecil dari $\alpha=0.05$ atau dengan $\mathrm{t}_{\text {hitung }}<\mathrm{t}_{\text {tabel }}$ $(5,694<2.019)$. Dengan demikian $\mathrm{H}_{\mathrm{a} 2}$ diterima dan $\mathrm{H}_{02}$ ditolak.

Secara parsial Kecerdasan Spiritual $\left(\mathrm{X}_{3}\right)$ berpengaruh signifikan terhadap Kinerja Karyawan (Y). Hal ini dibuktikan dengan nilai probabilitas signifikansi sebesar 0,008 yang lebih kecil dari $\alpha=0.05$ atau dengan $\mathrm{t}_{\text {hitung }}>\mathrm{t}_{\text {tabel }}$ $(2,813>2.019)$. Dengan demikian $\mathrm{H}_{\mathrm{a} 3}$ diterima dan $\mathrm{H}_{03}$ ditolak. 
Secara simultan Gaya Kepemimpinan $\left(\mathrm{X}_{1}\right)$, Motivasi $\left(\mathrm{X}_{2}\right)$ dan Lingkungan Kerja $\left(\mathrm{X}_{3}\right)$ berpengaruh sangat signifikan terhadap Kinerja Karyawan (Y). Hal ini dibuktikan dengan nilai probabilitas 0,000 lebih kecil dari 0.05, dengan nilai $F_{\text {hitung }}>F_{\text {tabel }}$ yaitu $105,105>2,23$.

Perusahaan disarankan untuk menambah pelatihan yang berkaitan problem solving agar karyawan dapat meningkatkan kemampuannya dalam memecahkan masalah yang dihadapi di kantor.

Perusahaan melakukan reviu terhadap jabatan/posisi karyawan yang membutuhkan kecerdasan angka sudah terisi oleh orang yang tepat. Serta memberikan sharing mengenai ketrampilan berhitung yang diterapkan di lingkungan kerja. Saran ini terkait dengan pertanyaan.

Karyawan diberikan pelatihan yang terkait dengan self awareness terutama meningkatkan kepercayaan diri. Hasil kuesioner menunjukkan hasil rendah pada pertanyaan "Saya tidak merasa canggung berada di sekitar orang-orang yang memiliki jabatan lebih tinggi”, pertanyaan tersebut berkaitan dengan kepercayaan diri.

Dilakukannya suatu forum komunikasi sehingga karyawan dapat mempunyai keterbukaan dan mampu bersikap adil di lingkungan kerja. Hal ini terkait dengan pertanyaan "Saya mampu memberikan penilaian secara objektif”.

Pelatihan ESQ dan pelatihan Anger Management untuk karyawan sangat disarankan, mengingat berdasarkan hasi penelitian kecerdasan emosional berpengaruh sangat signifikan terhadap kinerja karyawan.

Manajemen juga disarankan untuk mengadakan pelatihan yang dapat meningkatkan kesungguhan dan kejujuran, serta keterbukaan karyawan dalam menyelesaikan pekerjaan.

Bagi peneliti lain diharapkan dapat menambahkan variabel lain diluar model, sehingga dapat diketahui faktor-faktor lain yang mempengaruhi kinerja karyawan.

\section{DAFTAR PUSTAKA}

Sule, E. T \& Kurniawan Saefullah. 2005. Pengantar Manajemen. Jakarta: Prenada Media

Mangkunegara, A. A. A. P. 2012. Evaluasi Kinerja SDM. Bandung: Refika Aditama

Alam, R. 2007. Hubungan Empowerment Dengan Burnout Paramedic Rumah Sakit Rujukan. Unpublished Undergraduate Thesis

Hardiat. 2016. Pengaruh Kecerdasan Emosional, Kecerdasan Intelektual Dan Kecerdasan Spiritual Terhadap Kinerja Karyawan: Studi Pada Karyawan Marketing PT Nasmoco Bahan Motor Kota Yogyakarta. Fakultas Ekonomi Universitas Muhammadiyah. Yogyakarta

Hidayati, I. N, dkk. 2013. Kecerdasan Emosional Dan Kecerdasan Spiritual Pengaruhnya Terhadap Kepuasan Kerja dan Kinerja Karyawan: Studi di Lembaga Penjamin Mutu Pendidikan (LPMP). Fakultas Ekonomi dan Bisnis Universitas Brawijaya. Malang

Widodo, S. (2012). Cara Baru Memberdayakan Diri untuk Lebih Cepat Bahagia, Sukses dan 
Sejahtera. Jakarta: PT Gramedia Pustaka Utama

Trihandini, R. A. Fabiola Meirnayati. 2005. Analisis Pengaruh Kecerdasan Intelektual, Kecerdasan Emosi, dan Kecerdasan Spiritual Terhadap Kinerja Karyawan (Studi Kasus di Hotel Horison Semarang). Universitas Dipenogoro. Semarang

Robbins, S.P, Timothy A. Judge. 2014. Perilaku Organisasi: Jilid 1. Jakarta: Salemba Empat

Goleman, D. 2015. Emotional Intelligence: Mengapa Emotional intelligence Lebih Penting Daripada IQ. Jakarta: PT Gramedia Pustaka Utama

Moniaga, P. 2012. Analisis Pengaruh Kecerdasan Emosional, Kecerdasan Spiritual dan Kecerdasan Intelektual Terhadap KInerja Karyawan: Studi Kasus Pada PT Bank Sulut Kantor Pusat. Fakulktas Ekonomi dan Bisnis Universitas Sam Ratulangi. Manado

Eckersley, R. 2000. Spiritually, Progress, Meaning, and Value. Paper Presented $3^{\text {rd }}$ Annual Conferece of Spiritually, Leadership and Management Ballarad

Wirawan. 2015. Evaluasi Kinerja Sumber Daya Manusia: Teori, Aplikasi, dan Penelitian. Jakarta: Salemba Empat

Wijaya. C. A. 2014. Analisa Pengaruh Kecerdasan Intelektual, Kecerdasan Emosional, dan Kecerdasan Spiritual Terhadap Kinerja Karyawan di Hotel "X". Manajemen Perhotelan Universitas Petra. Surabaya

Sukidi, I. 2002. Kecerdasan Spiritual: Mengapa SQ Lebih Penting dari IQ dan EQ. Jakarta: PT Gramedia Pustaka Utama

Sugiyono, 2016, Metode Penelitian Kuantitatif, Kualitatif, dan R\&D, Bandung: Alfabeta

Indriantoro, Nur. dan Supomo, Bambang., 2012, Metodolgi Penelitian Bisnis Untuk
Akuntansi dan Manajemen, Yogyakarta, Fakultas Ekonomika dan Bisnis UGM

Supranto, J. 2016, Statistik, Teori dan Aplikasi, Metode Riset, Jakarta, Rineka Cipta 